Check for updates

Cite this: RSC Adv., 2018, 8, 28453

Received 22nd June 2018

Accepted 30th July 2018

DOI: $10.1039 / c 8 r a 05355 c$

rsc.li/rsc-advances

\section{Effect of stereocomplex crystal and flexible segments on the crystallization and tensile behavior of poly(L-lactide)}

\author{
Xiaolu Li, ${ }^{a}$ Xiuqin Zhang, (DD *a Guoming Liu, (D) ${ }^{\text {b }}$ Zhongkai Yang, ${ }^{\text {a }}$ Bo Yang, ${ }^{a}$ Yue Qi, ${ }^{a}$ \\ Rui Wang ${ }^{\star a}$ and De-Yi Wang (iD ${ }^{c}$
}

The effects of poly(ethylene glycol) (PEG) and/or poly(D-lactide) (PDLA) blocks on the crystallization and mechanical properties of poly(L-lactide) (PLLA) were investigated systematically via differential scanning calorimetry (DSC), polarized optical microscopy (POM), wide-angle X-ray diffraction (WAXD) and tensile testing. The structural evolution during uniaxial stretching of the obtained blends above the glass transition temperature was studied by in situ WAXD. It was observed that the stereocomplex (SC) crystals promoted the nucleation of PLLA homocrystals ( $\alpha / \alpha^{\prime}$ crystal), and flexible PEG blocks could enhance the spherulitic growth rate. The PLLA/PDLA-PEG-PDLA had a higher elongation at break than that of PLLA/ PDLA without significant loss in tensile strength and stiffness. In situ WAXD showed that the PLLA/PDLAPEG-PDLA crystallized faster during stretching. It was shown that the incorporation of SC crystals and flexible PEG blocks could not only accelerate the crystallization but also improve the toughness of PLLA.

\section{Introduction}

Poly(lactide) (PLA), one of the representative biodegradable materials, has found a vast number of applications in different areas, such as textiles, medicine and packaging..$^{1-3}$ However, PLA possesses some intrinsic shortcomings, including low crystallization rate, poor heat resistance, and toughness, which limit its applications. It is believed that high-performance PLA materials can be achieved by adjusting the crystalline structure by processing, blending with other polymers or adding organic or inorganic additives. ${ }^{4-7}$

Many nanofillers have been applied to tailor the crystallization rate in PLA, such as carbon nanotubes, ${ }^{8}$ graphene or graphene oxide ${ }^{7,9}$ and nanoclay. ${ }^{10}$ However, those additives may raise environmental or health issues which hinder them from applications in medical areas or food packaging.

Ikada et al. ${ }^{11}$ reported that a stereocomplex (SC) crystal can be obtained by blending poly(D-lactide) (PDLA) with poly(L-lactide) (PLLA). With a melting point $50{ }^{\circ} \mathrm{C}$ higher than that of PLA homocrystals (HC), SC crystals provide a promising solution to heat resistant PLA materials..$^{12}$ More importantly, SC crystals

${ }^{a}$ Beijing Key Laboratory of Clothing Materials $R \& D$ and Assessment, Beijing Engineering Research Center of Textile Nanofiber, School of Materials Science \& Engineering, Beijing Institute of Fashion Technology, Beijing 100029, China. E-mail: clyzxq@bift.edu.cn; clywangrui@bift.edu.cn

${ }^{b}$ CAS Key Laboratory of Engineering Plastics, CAS Research/Education Center for Excellence in Molecular Sciences, Institute of Chemistry, Chinese Academy of Sciences, Beijing 100190, China

${ }^{c} I M D E A$ Materials Institute, Madrid, 28906, Spain can effectively mediate the crystallization rate of PLA while maintaining the biocompatibility. Anderson et al. ${ }^{13}$ found that the nucleating efficiencies increased by up to about $100 \%$ by adding 3 wt $\%$ of PDLA into PLLA, which suggested the nucleation effect of SC crystals was better than that of talc. Besides, Yin et al. ${ }^{14}$ also showed that PDLA had better nucleation efficiency than talc for PLLA under static and stretching condition. Tsuji et al. ${ }^{15}$ demonstrated that the crystallization rate and nucleation density of PLLA $\alpha$ crystals could be significantly increased with the aid of a small amount of SC crystals.

Although SC crystals could promote the crystallization of PLLA by heterogeneous nucleation, ${ }^{16}$ the toughness is still quite low for PLLA with high crystallinity. Introducing flexible segments including poly( $\varepsilon$-caprolactone) (PCL), ${ }^{17}$ poly(butylenes succinate) (PBS), ${ }^{18,19}$ poly(butylene succinate-co-adipate) $(\mathrm{PBSA})^{20}$ and poly(ethylene glycol) (PEG) ${ }^{21-24}$ into PLLA is an effective way to improve the toughness. However, blending PLLA with flexible polymers generally results in a significant decrease in modulus, tensile strength and thermal deflection temperature of PLLA. To settle these inevitable shortcomings, new strategies which could both improve crystallization rate and toughness are favoured.

It has been found that the introduction of PDLA block copolymers with soft chains as the modifier of PLLA could enhance the thermal and mechanical stability of PLLA without compromising the stiffness and tensile strength. ${ }^{21,25}$ Liu et al. ${ }^{26}$ reported that the tensile strength and elongation at break of PLLA were effectively improved when the content of PDLA-PEGPDLA block copolymer reached up to $30 \mathrm{wt} \%$. In our previous work, the effect of the content of PDLA-PEG-PDLA on the 
properties of PLLA has been investigated and the tensile elongation at break of PLLA could reach up to $200 \%$ at $50{ }^{\circ} \mathrm{C} .{ }^{27}$ Song et $a{ }^{28}{ }^{28}$ revealed that the introduction of PEG segment was beneficial to the formation of SC crystals and improvement of crystallization rate in PLLA/PDLA-PEG-PDLA.

Despite those recent studies, it is still unclear how the SC crystals and flexible PEG blocks affect the structure and properties of PLLA, especially the structural evolution of those materials under deformation. Herein, PLLA/PLLA-PEG-PLLA, PLLA/PDLA, and PLLA/PDLA-PEG-PDLA blends were selected for a systematic study on the effect of PDLA and PEG on the crystalline structure and kinetics, tensile properties and deformation mechanism of those materials. Different stretching temperatures were selected, covering the range of room temperature to $80^{\circ} \mathrm{C}$, considering the application environments as plastics.

\section{Experimental section}

\section{Materials}

PLLA (optical purity $=99.7 \%, M_{\mathrm{n}}=95 \mathrm{~kg} \mathrm{~mol}^{-1}$, PDI $=1.43$ ) was obtained from Zhejiang Haizheng Biomaterials Co., Ltd. $\operatorname{PDLA}\left(M_{\mathrm{n}}=12 \mathrm{~kg} \mathrm{~mol}^{-1}\right.$ and PDI = 1.16) and PLLA $_{5 \mathrm{k}}-b-\mathrm{PEG}_{4 \mathrm{k}}-b-$ PLLA $_{5 \mathrm{k}}$ and PDLA $_{5 \mathrm{k}}-b-\mathrm{PEG}_{4 \mathrm{k}}-b-\mathrm{PDLA}_{5 \mathrm{k}}$ were purchased from Jinan Daigang Biomaterial Co., Ltd. Antioxidant (1010) was purchased from BASF Co., Ltd.

\section{Samples preparation}

All the polymer samples were dried at $80{ }^{\circ} \mathrm{C}$ in a vacuum oven for $24 \mathrm{~h}$. The composites were prepared by melt extrusion with an internal mixer (Haake Rheomix OS) at $190{ }^{\circ} \mathrm{C}$ with a rotating speed of $50 \mathrm{rpm}$ for $5 \mathrm{~min}$. The weight ratio of PLLA/PDLA, PLLA/PLLA-PEG-PLLA, and PLLA/PDLA-PEG-PDLA blends was fixed to 90/10 (Table 1). $0.5 \mathrm{~mm}$ thick plates of neat PLLA and its blends were prepared using a compression molding machine at a temperature of $190{ }^{\circ} \mathrm{C}$ (for neat PLLA) or $230{ }^{\circ} \mathrm{C}$ (for PDLA-containing blends). The molding pressure was $40 \mathrm{MPa}$ and the pressure holding time was $3 \mathrm{~min}$. Subsequently, the samples were cooled down quickly to room temperature in an ice-water bath. The specimens were cut into dumbbell shape with $40 \mathrm{~mm}$ in length, $2 \mathrm{~mm}$ in width, and $0.5 \mathrm{~mm}$ in thickness.

\section{Measurement and characterization}

The melting and crystallization behavior of PLLA and the blends were performed with a TA Q2000 DSC (TA Instruments, USA)

Table 1 Composition information of PLLA and its blends

\begin{tabular}{lrll}
\hline Samples & PLLA/wt\% & PDLA/wt\% & PEG/wt\% \\
\hline PLLA & 100 & - & - \\
PLLA/PLLA-PEG-PLLA & 90 & - & 2.86 \\
PLLA/PDLA & 90 & 7.14 & - \\
PLLA/PDLA-PEG-PDLA & 90 & 7.14 & 2.86
\end{tabular}

under nitrogen atmosphere at $50 \mathrm{~mL} \min ^{-1}$. The instrument was calibrated with indium before measurements. About 5$10 \mathrm{mg}$ samples were weighed and sealed in an aluminium pan, heated from $30{ }^{\circ} \mathrm{C}$ to $250{ }^{\circ} \mathrm{C}$ and held for $3 \mathrm{~min}$ to eliminate the thermal history. The samples were first cooled to $30{ }^{\circ} \mathrm{C}$ at $10{ }^{\circ} \mathrm{C} \mathrm{min}{ }^{-1}$, and then reheated to $250{ }^{\circ} \mathrm{C}$ at $10{ }^{\circ} \mathrm{C} \mathrm{min}^{-1}$.

The spherulitic morphologies of PLLA and the blends were observed with a polarized optical microscope (Olympus BX51, Japan) equipped with a Linkam hot stage. The samples were sandwiched between two glass plates, kept in the melt at $230{ }^{\circ} \mathrm{C}$ for $3 \mathrm{~min}$ to eliminate the thermal history. Then, the specimens were cooled to $120{ }^{\circ} \mathrm{C}$ at a cooling rate of $60{ }^{\circ} \mathrm{C} \min ^{-1}$ for isothermal crystallization.

X-ray diffraction (XRD) measurements were carried out using a Bruker AXS D8 diffractometer with $\mathrm{Cu} \mathrm{K} \alpha$ radiation $(\lambda=1.54$ $\AA)$. The 2D-WAXD patterns were collected by the twodimensional detector VANTEC-500. The exposure time was $300 \mathrm{~s}$ and the sample-to-detector distance was $85.6 \mathrm{~mm}$.

The samples were stretched on a Linkam TST 350 hotstage (Linkam Scientific Instruments, Ltd., U.K.) at $30{ }^{\circ} \mathrm{C}, 40{ }^{\circ} \mathrm{C}$, $45{ }^{\circ} \mathrm{C}, 55^{\circ} \mathrm{C}, 58^{\circ} \mathrm{C}$ and $80^{\circ} \mathrm{C}$, respectively. The crosshead speed was $150 \mu \mathrm{m} \mathrm{s}^{-1}$. Engineering stress $(\sigma)$ and engineering strain $(\varepsilon)$ were calculated according to $\sigma=F / A$ and $\varepsilon=\left(L-L_{0}\right) / L_{0}$ respectively, where $F$ is the force, $L$ is the sample length, $L_{0}$ is the initial sample length and $A$ is the initial cross section area.

In situ X-ray scattering measurements were carried out at $80{ }^{\circ} \mathrm{C}$. The patterns were collected at every $2 \mathrm{~mm}$ until the mini tensile bars were stretched to $200 \%$ strain. The image acquisition time was $40 \mathrm{~s}$. All the images were corrected for background scattering, air scattering, and absorption. Two-dimensional patterns were converted into one-dimensional scattering curves along the angle $0-360^{\circ}$. The relative fraction of different phases was calculated according to:

$$
\begin{aligned}
X_{\alpha} & =\frac{I_{\alpha}}{I_{\alpha}+I_{\mathrm{SC}}+I_{\mathrm{amor}}} \\
X_{\mathrm{SC}} & =\frac{I_{\mathrm{SC}}}{I_{\alpha}+I_{\mathrm{SC}}+I_{\mathrm{amor}}} \\
X & =X_{\alpha}+X_{\mathrm{SC}}
\end{aligned}
$$

where $X_{\alpha}, X_{\mathrm{SC}}$, and $X$ represent the phase content of $\alpha$ crystals, SC crystals and overall crystallinity, respectively. $I_{\alpha}$ and $I_{\mathrm{sc}}$ stand for the sum of the integrated scattering intensity of the reflections of $\alpha$ crystals and SC crystals. $I_{\text {amor }}$ indicates the integrated intensity of the amorphous halo. The quantitative degrees of orientation of the lattice plane $(200) /(110)$ in uniaxially oriented samples were calculated according to the Hermans formula: ${ }^{\mathbf{9 9 , 3 0}}$

$$
f_{(200) /(110)}=\frac{3\left\langle\cos ^{2} \varphi\right\rangle-1}{2}
$$

where, $\varphi$ is the angle between the normal direction of the crystal plane and the reference axis. $\left\langle\cos ^{2} \varphi\right\rangle$ is defined as: 


$$
\left\langle\cos ^{2} \varphi\right\rangle=\frac{\int_{0}^{\frac{\pi}{2}} I(\varphi) \cos ^{2} \varphi \sin \varphi \mathrm{d} \varphi}{\int_{0}^{\frac{\pi}{2}} I(\varphi) \sin \varphi \mathrm{d} \varphi}
$$

where, $I(\varphi)$ is the scattering intensity along the angle $\varphi$.

\section{Results and discussion}

\section{Crystallization behavior}

The crystallization behavior of PLLA and its blends are investigated by DSC. As shown in Fig. 1A, the crystallization temperature of PLLA/PDLA appears at $120.3{ }^{\circ} \mathrm{C}$, which is higher than that of neat PLLA and PLLA/PLLA-PEG-PLLA blend. Besides, a new peak appears at $\sim 220{ }^{\circ} \mathrm{C}$, which indicates the formation of SC crystals in PLLA/PDLA. The presence of SC crystals acts as heterogeneous nucleating seeds for the homocrystals of PLLA. Furthermore, the crystallization temperature of the homocrystals in PLLA/PDLA-PEG-PDLA blend increases further to 126.3 ${ }^{\circ} \mathrm{C}$. The subsequent heating curves of PLLA and PLLA/ PLLA-PEG-PLLA show a baseline shift and an endothermic peak located at $58{ }^{\circ} \mathrm{C}$ and $175^{\circ} \mathrm{C}$, corresponding to glass transition and melting of $\alpha / \alpha^{\prime}$ crystals. Besides, two exothermic peaks at $95{ }^{\circ} \mathrm{C}$ and $157^{\circ} \mathrm{C}$ can be assigned to cold crystallization and the transition from $\alpha^{\prime}$ to $\alpha$ phase $^{31,32}$ respectively (Fig. 1B). For PLLA/PDLA and PLLA/PDLA-PEG-PDLA blends, the cold crystallization peak and the $\alpha^{\prime}$ to $\alpha$ transition peak disappear, while the endothermic peak of SC crystals appears, indicating that crystallization is more complete in the PDLA-containing samples during cooling and the more stable $\alpha$ crystals are formed.

The isothermal crystallization kinetics of samples at the temperature ranges of $120-150{ }^{\circ} \mathrm{C}$ are further studied by DSC (Fig. 2). For all the four selected temperatures, the crystallization time decreases with the sequence of PLLA > PLLA/PLLAPEG-PLLA > PLLA/PDLA > PLLA/PDLA-PEG-PDLA. Furthermore, the crystallization time of the samples gradually increases with crystallization temperature. Moreover, the halfcrystallization time of pure PLLA and PLLA/PLLA-PEG-PLLA increases more sharply than that of PLLA/PDLA and PLLA/ PDLA-PEG-PDLA blends (Fig. 3). When the crystallization temperature is above $140{ }^{\circ} \mathrm{C}$, it is difficult to nucleate in the
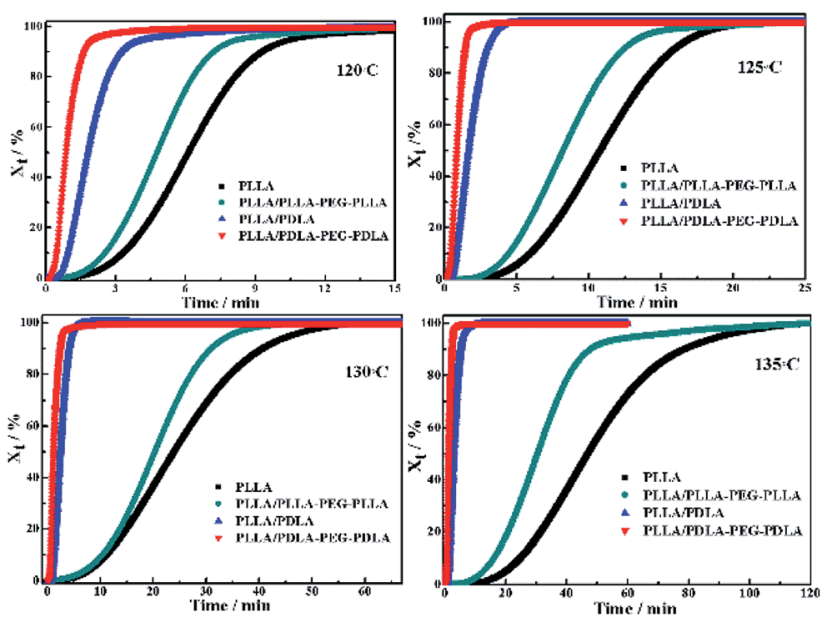

Fig. 2 The relative crystallinity $\left(X_{t}\right)$ of PLLA and blends isothermally crystallized at different temperatures as a function of crystallization time.

PLLA and PLLA/PLLA-PEG-PLLA blends and the crystallization rate is too slow to be measured. The PEG in the PLLA-PEGPLLA and PDLA-PEG-PDLA can act as a plasticizer to accelerate the crystallization of PLLA homocrystals. Besides, the formation of SC crystals after blending PDLA is beneficial to the crystallization of PLLA homocrystals by heterogeneous nucleation effect.

All specimens after isothermal crystallization at $120{ }^{\circ} \mathrm{C}$ exhibit typical spherulitic morphology (Fig. 4). The nucleation densities of PLLA and PLLA/PLLA-PEG-PLLA are relatively small. As shown in Fig. 5, the spherulitic growth rate is higher when PEG segments are introduced into the system, possibly because the chain mobility of PLLA is increased..$^{33}$ Tiny crystals are observed in PLLA/PDLA and PLLA/PDLA-PEG-PDLA blends, indicating larger nucleation densities. Besides, the spherulitic density of the PLLA/PDLA-PEG-PDLA is higher than that of PLLA/PDLA.

\section{Tensile properties of the compression molded specimen}

The WAXD intensity profiles of the compression molded specimen are displayed in Fig. 6. The pure PLLA and PLLA/PLLAPEG-PLLA are amorphous and no diffraction peak is visible. In
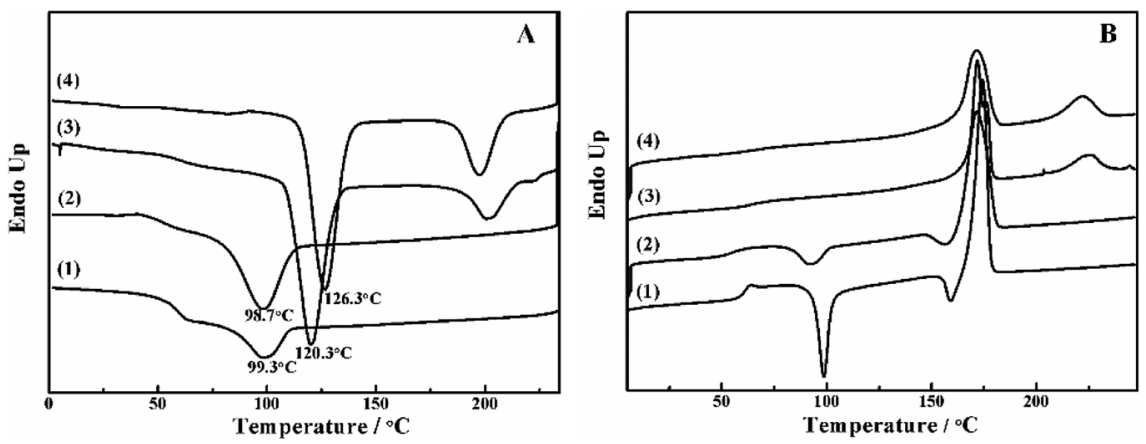

Fig. 1 DSC curves of PLLA (1), PLLA/PLLA-PEG-PLLA (2), PLLA/PDLA (3) and PLLA/PDLA-PEG-PDLA (4) blends in (A) the cooling and (B) the second heating processes. The heating and cooling rate was $10{ }^{\circ} \mathrm{C} \mathrm{min}-1$. 


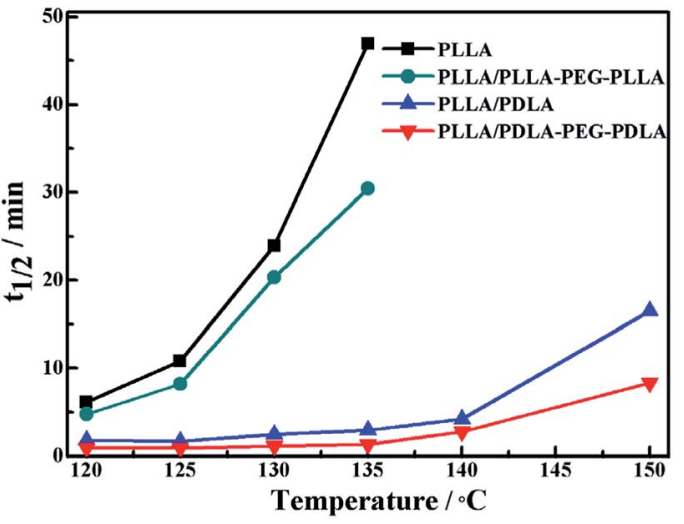

Fig. 3 The half-crystallization time of PLLA and blends isothermally crystallized at different temperatures.

contrast, the PLLA/PDLA and PLLA/PDLA-PEG-PDLA blends exhibit three peaks located at $2 \theta=11.9^{\circ}, 21^{\circ}$, and $23^{\circ}$, respectively, which correspond to the (110), (300)/(030) and (220) of SC crystals. $^{34}$

Stress-strain curves of the polymer stretched at different temperatures are shown in Fig. 7. The polymer chains of PLLA are virtually frozen when the stretching temperature is wellbelow the $T_{\mathrm{g}}$ of PLLA $\left(30^{\circ} \mathrm{C}\right.$ and $\left.40{ }^{\circ} \mathrm{C}\right)$, resulting in poor tensile properties and brittle fracture. When the stretching temperature increases to $45{ }^{\circ} \mathrm{C}$, the necking phenomenon appears and the elongation at break of PLLA/PLLA-PEG-PLLA and PLLA/PDLA-PEG-PDLA blends increases up to $480 \%$ and $390 \%$, respectively. It can be attributed to the plasticization effect of PEG segments in those samples, i.e., the PEG flexible chains can act as a plasticizer to facilitate the movement of PLLA chains. When the stretching temperature is increased to $55{ }^{\circ} \mathrm{C}$, the polymers, except for PLLA/PDLA blend, show very high elongation. However, PLLA/PDLA has the highest yield strength as compared with other samples, which can be

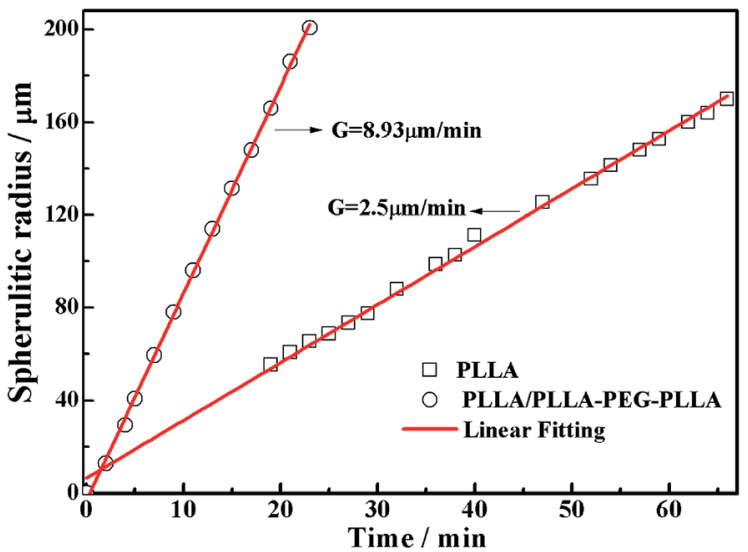

Fig. 5 Plots of spherulitic radius against time during isothermal crystallization at $120^{\circ} \mathrm{C}$.

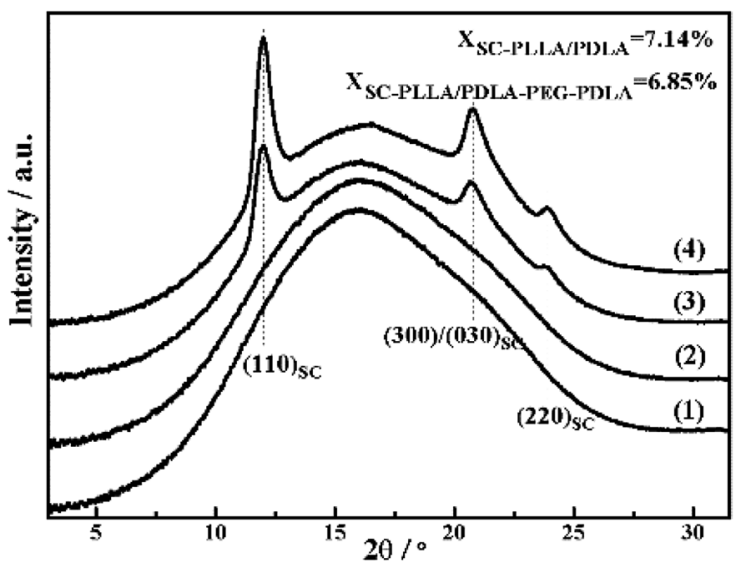

Fig. 6 1D-WAXD intensity profiles of initial PLLA (1) and PLLA/PLLAPEG-PLLA (2), PLLA/PDLA (3) and PLLA/PDLA-PEG-PDLA (4) blends.

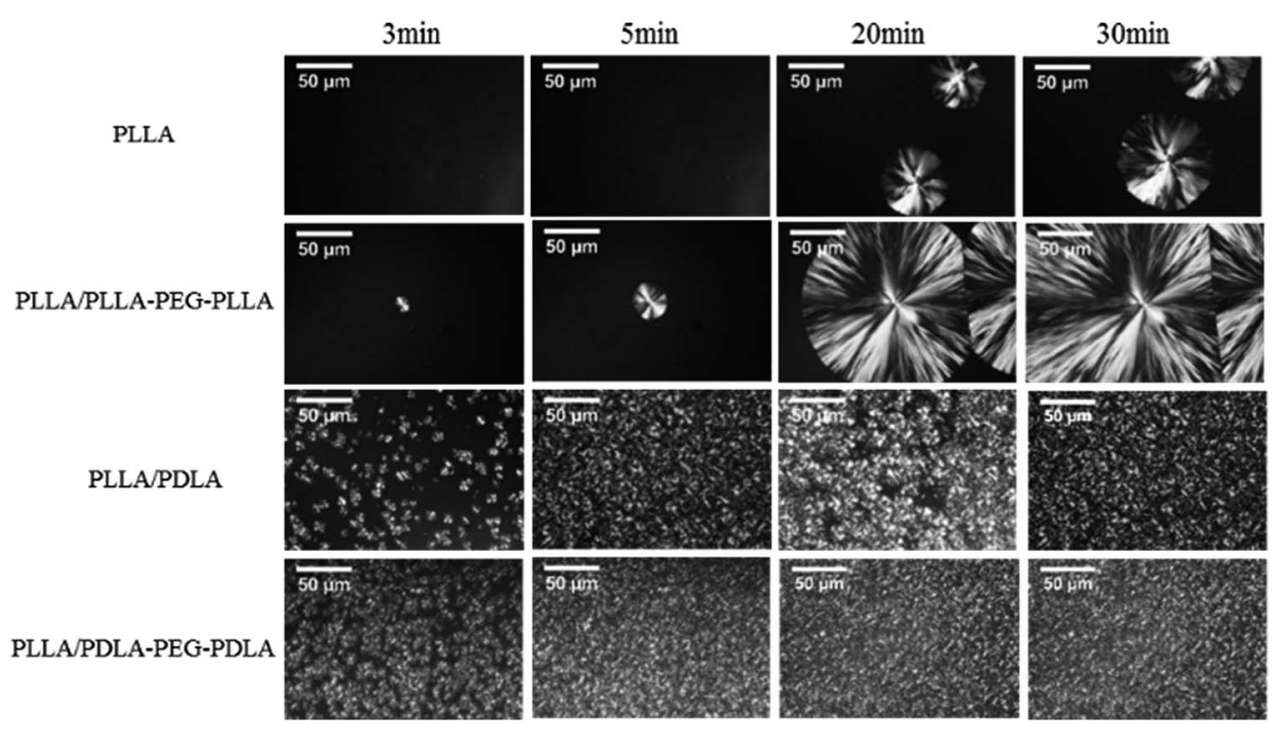

Fig. 4 POM images for PLLA and its blends isothermally crystallized at $120{ }^{\circ} \mathrm{C}$ for different time. 

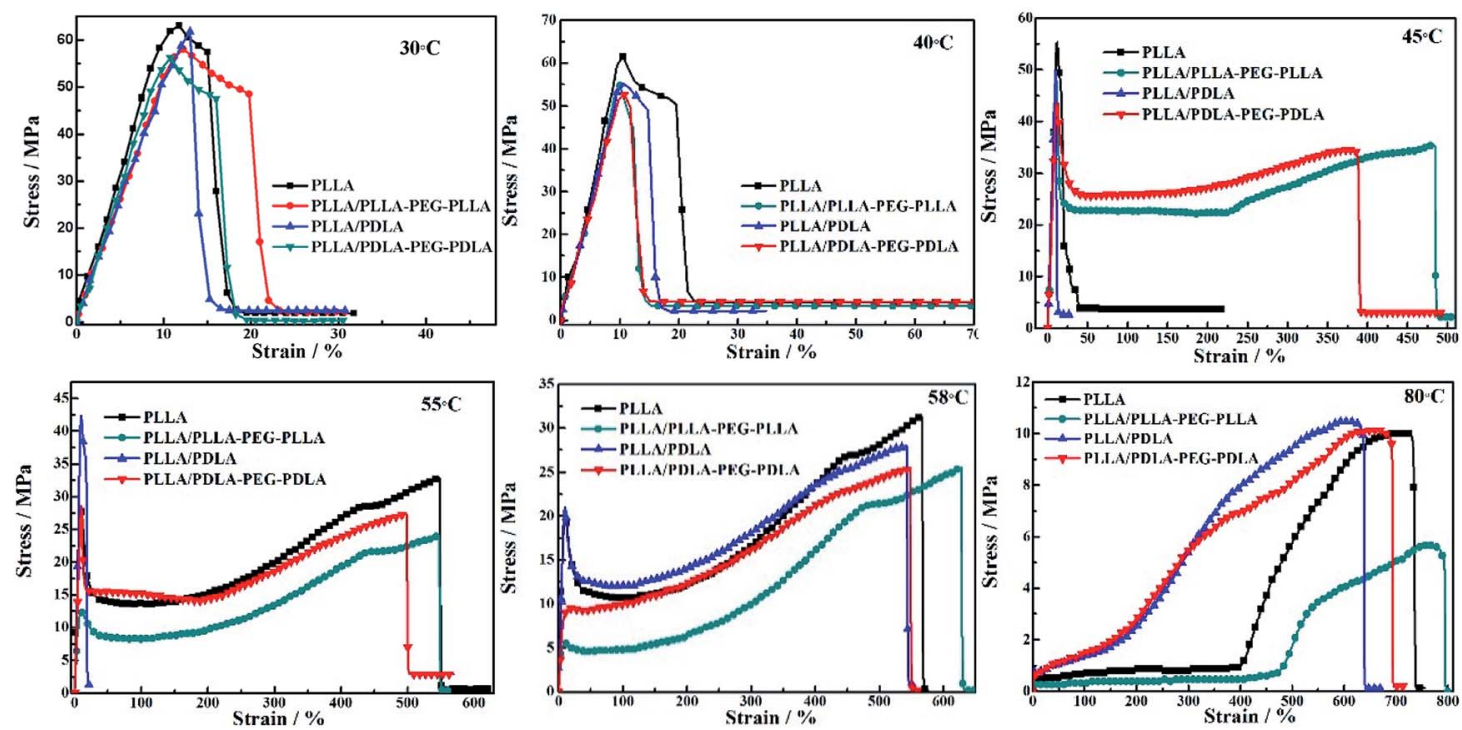

Fig. 7 Engineering stress-strain curves of PLLA and blends stretched at different temperatures. The stretching rate was $150 \mu \mathrm{m} \mathrm{s}{ }^{-1}$.

ascribed to the presence of SC crystals in PLLA/PDLA. These results suggest that both SC crystals and soft segments affect the tensile properties of PLLA. When the temperature is close to $T_{\mathrm{g}}$ of PLLA $\left(58{ }^{\circ} \mathrm{C}\right)$, all the samples exhibit typical necking phenomenon. When the temperature is further increased to $80^{\circ} \mathrm{C}$, the PLLA chains are in the rubbery state, therefore, no yielding is observed and strain-induced crystallization occurs. The introduction of SC crystals and soft segments affects the microstructure formation mechanism and in turn, influences the mechanical properties.

\section{In situ WAXD during stretching}

The in situ WAXD technique is applied to further explore the microstructure evolution of the samples during stretching at $80{ }^{\circ} \mathrm{C}$. The stress-strain curves of pure PLLA and its blends during the in situ WAXD measurement are shown in Fig. 8. The pure PLLA displays a rubber-like behaviour at low strain

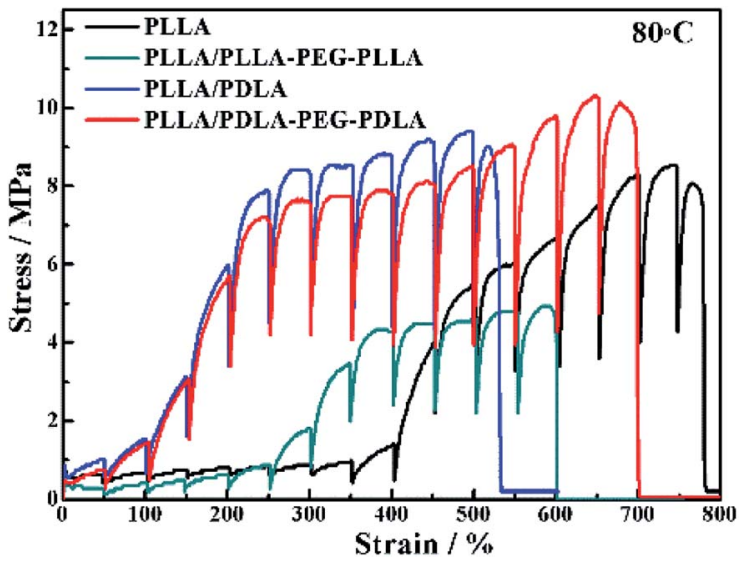

Fig. 8 Engineering stress-strain curves of PLLA and blends stretched at $80^{\circ} \mathrm{C}$. The stretching rate was $150 \mu \mathrm{m} \mathrm{s}^{-1}$.
$(<400 \%)$ and a low elastic modulus. The stress of PLLA increases slightly with the increase of strain. The stress of PLLA/PLLAPEG-PLLA and PLLA/PDLA blend increases sharply when the strain reaches $300 \%$ and $100 \%$, respectively. The introduction of soft segments can improve the elongation at break from $540 \%$ (PLLA/PDLA) to 700\% (PLLA/PDLA-PEG-PDLA). There is some slight difference between Fig. 7 and 8 due to the annealing effect. However, the general features are the same.

2D-WAXD patterns and the corresponding 1D WAXD intensity profiles for different strains during stretching are shown in Fig. 9 and 10, respectively. New diffraction arcs appear in the equatorial direction with the increasing strain, which is assigned to the (200)/(110) and (203) crystal planes of PLLA homocrystals. The critical strains for homocrystal formation are $350 \%$ for pure PLLA, $250 \%$ for PLLA/PLLA-PEG-PLLA, $100 \%$ for PLLA/PDLA, and 20\% for PLLA/PDLA-PEG-PDLA, respectively. These results indicate that the PEG and SC crystals can promote the crystallization of PLLA both under static condition and during stretching.

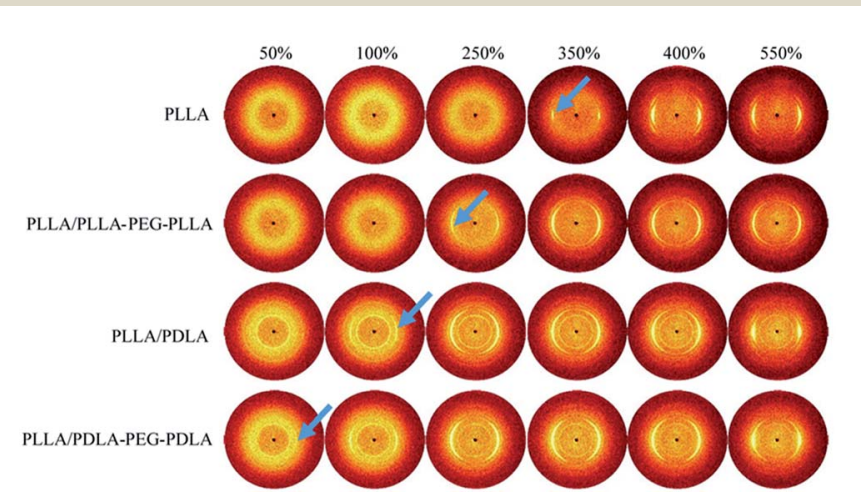

Fig. 9 WAXD patterns of PLLA and the blends with different strains at $80^{\circ} \mathrm{C}$. The stretching direction was vertical with a speed of $150 \mu \mathrm{m} \mathrm{s}^{-1}$. Arrows indicate the diffraction of homocrystals. 

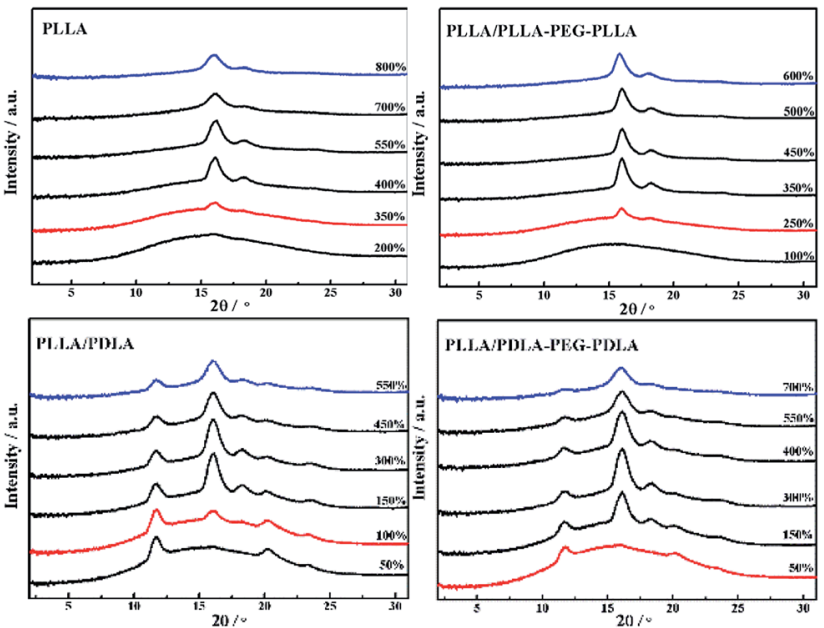

Fig. 10 1D-WAXD intensity profiles of PLLA and blends stretched at $80^{\circ} \mathrm{C}$. The stretching speed was $150 \mu \mathrm{m} \mathrm{s}^{-1}$.

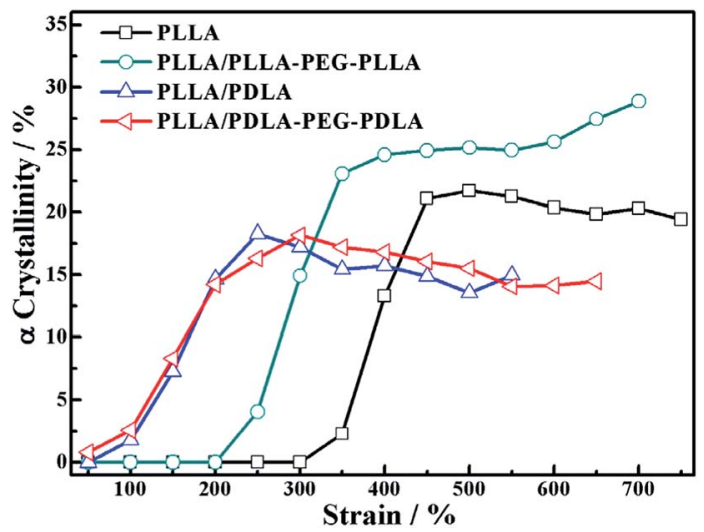

Fig. 11 The variation of $\alpha$ crystallinity of specimens as a function of strain during stretching at $80^{\circ} \mathrm{C}$.

Because of the different critical strains of $\alpha$ crystals during stretching, the structure under the same strain condition is different, which results in various stress (Fig. 11). The contents of $\alpha$ crystals increase rapidly at low strains due to the presence of SC crystals in PLLA/PDLA and PLLA/PDLA-PEG-PDLA blends. The final content of $\alpha$ crystals of PDLA-containing blends is lower than those of pure PLLA and PLLA/PLLAPEG-PLLA. It can be ascribed to the fact that a fraction of the PLLA chains is consumed by SC crystals.

The orientation parameters of $(200) /(110)_{\alpha}$ crystal plane of stretched samples are shown in Fig. 12. It is easier to reach higher orientation when the crystallization of PLLA occurs at higher strains. Therefore, the pure PLLA has the highest degree of orientation. The introduction of PLLA-PEG-PLLA, PDLA and PDLA-PEG-PDLA reduce the critical strain of crystallization, resulting in a lower orientation of $\alpha$ crystals. In addition, the low fracture strains of PLLA/PDLA, and PLLA/ PLLA-PEG-PLLA blends also lead to lower final crystal orientation.

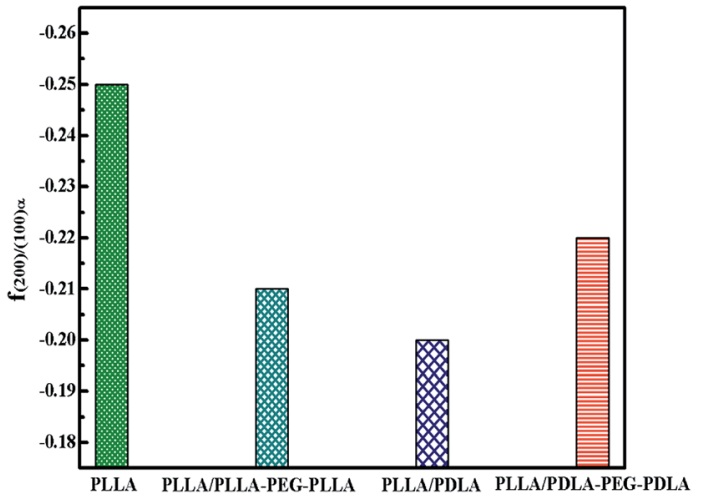

Fig. 12 The orientation parameter of $(200 / 110)_{\alpha}$ crystal plane for neat PLLA and its blends after uniaxial stretching at $80^{\circ} \mathrm{C}$, respectively.

\section{Crystallization after step-strain}

To further investigate the effect of SC crystals and flexible segments on the crystallization of specimens, in situ WAXD with step-strain deformation are measured (Fig. 13). The samples are stretched to a constant strain of $200 \%$ at a stretching rate of 150 $\mu \mathrm{m} \mathrm{s}^{-1}$. The patterns in the first column show that neat PLLA and PLLA/PLLA-PEG-PLLA are amorphous after stretched to $200 \%$. After $190 \mathrm{~s}$, a weak (110/200) $)_{\alpha}$ diffraction arc appears in PLLA/PLLA-PEG-PLLA, slightly earlier than the onset time for PLLA (255 s), indicating that the PEG facilitates PLLA crystallization. The PLLA/PDLA and PLLA/PDLA-PEG-PDLA show strong $(200 / 110)_{\alpha}$ and $(203)_{\alpha}$ reflections immediately after stretching. More detailed information is shown in the 1D WAXD intensity profiles (Fig. 14).

As shown in Fig. 15, the crystallinity of PLLA/PDLA-PEGPDLA is $11.18 \%$ at $65 \mathrm{~s}$, which is higher than that of PLLA/PDLA $(5.62 \%)$. All the above results indicate that both the SC crystals and PEG blocks contribute to the crystallization of PLLA. Based on the above results, a schematic illustration of the effect of SC crystals and flexible PEG blocks on PLLA crystallization under strain is depicted in Fig. 16. The PLLA and the PLLA/PLLA-PEGPLLA blend are amorphous, while SC crystals are present in the

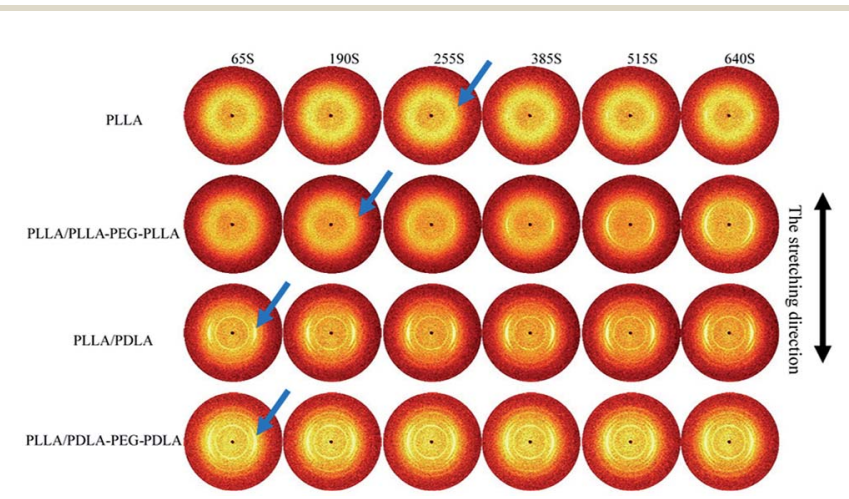

Fig. 13 Selected 2D WAXD patterns of pure PLLA and blends during isothermal crystallization at $80{ }^{\circ} \mathrm{C}$ after uniaxial stretching to $200 \%$. The stretching speed was $150 \mu \mathrm{m} \mathrm{s}^{-1}$. The stretching direction was vertical. 

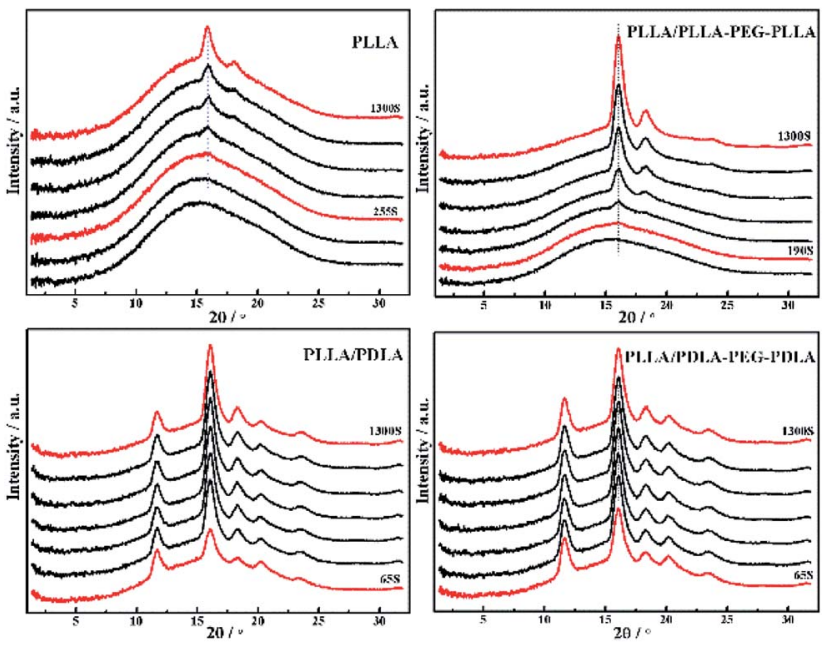

Fig. 14 1D WAXD intensity profiles of PLLA and blends during isothermal crystallization at $80{ }^{\circ} \mathrm{C}$ after uniaxial stretching to $200 \%$.

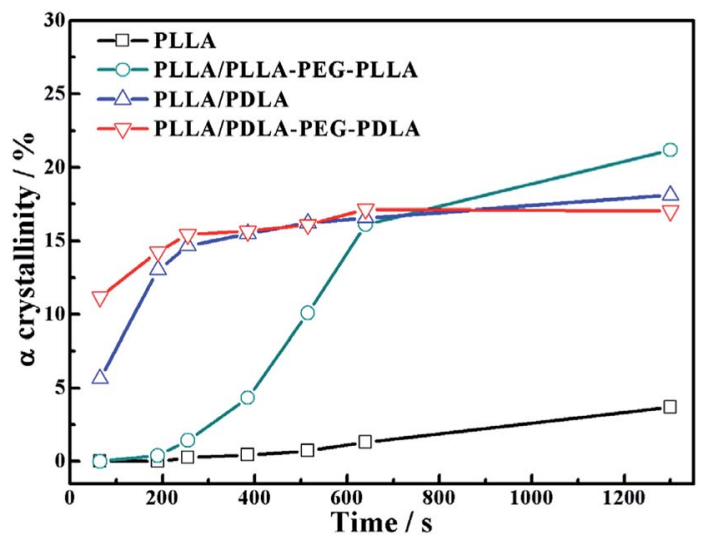

Fig. 15 The variation of $\alpha$ crystal in neat and blends as a function of time during isothermal process at $80^{\circ} \mathrm{C}$ after step-stretching to $200 \%$. The stretching speed was $150 \mu \mathrm{m} \mathrm{s}^{-1}$.

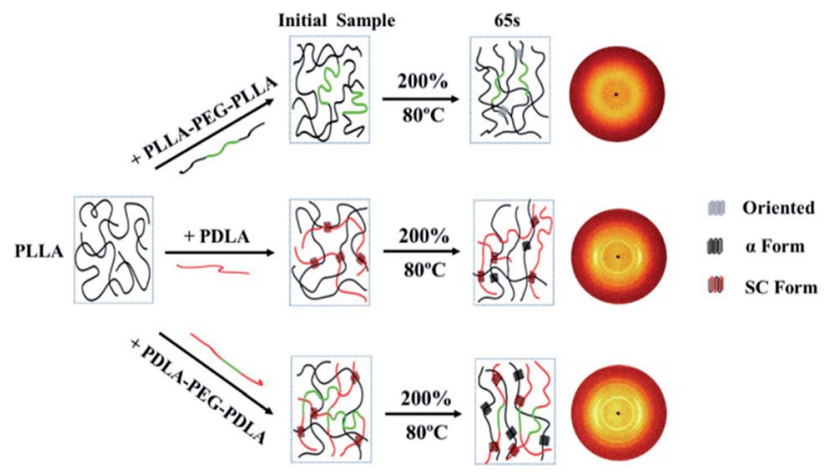

Fig. 16 Schematic illustration of structural evolution of PLLA and blends under $80^{\circ} \mathrm{C}$ after step-strain.

PDLA containing blends (PLLA/PDLA and PLLA/PDLA-PEGPDLA). When stretched to $200 \%$ at $80{ }^{\circ} \mathrm{C}$, no $\alpha$ crystals are detected in the PLLA/PLLA-PEG-PLLA blend in the beginning (after $65 \mathrm{~s}$ ). However, due to the nucleation effects of SC crystals, the PLLA/PDLA blend and the PLLA/PDLA-PEG-PDLA blend form $\alpha$ crystals immediately, with the same thermal and deformation history. The crystallization rate is the highest for the PLLA/PDLA-PEG-PDLA blend because of the coexistence of nucleation agent and plasticizer. With the same processing condition, a higher crystallization rate will generally result in a higher crystallinity, which will impart the materials with higher stiffness and strength. The flexible PEG blocks could act as "molecular lubricants", thus increasing the toughness of the PLLA blend.

\section{Conclusion}

In this work, by adding ABA block copolymers, the effect of flexible PEG blocks and PDLA chains on the crystallization and mechanical properties of PLLA was studied by DSC, POM, and WAXD. It was observed that SC crystals promote the nucleation of $\alpha$ crystals and PEG blocks attribute to a higher spherulitic growth rate. With the combination of PEG and PDLA chains, the crystallization temperature of PLLA/PDLA-PEG-PDLA increased significantly. The elongation at break of PLLA/PDLA-PEG-PDLA could reach $400 \%$ with the help of PEG segments at temperatures higher than $45{ }^{\circ} \mathrm{C}$, while the stiffness was largely maintained due to the enforcing effect of SC crystals. By in situ WAXD during stretching, the critical strains of $\alpha$ crystal formation at $80{ }^{\circ} \mathrm{C}$ in different samples decreased in the following order: PLLA > PLLA/PLLA-PEG-PLLA > PLLA/PDLA > PLLA/PDLAPEG-PDLA. During isothermal crystallization after step-strain, the content of $\alpha$ crystals of PLLA/PDLA-PEG-PDLA was significantly higher than that of other blends at $65 \mathrm{~s}$. All the results suggested that the coexistence of SC crystals and soft chains could effectively improve the toughness and crystallization rate of PLLA, thus enhancing the comprehensive properties of PLLA.

\section{Conflicts of interest}

There are no conflicts to declare.

\section{Acknowledgements}

The work was financially supported by the National Key Research and Development Program of China (2017YFB0309300), the National Natural Science Foundation of China (Grant No. 51673003, 51628301) and the Beijing Great Wall Scholars Incubator Program (No. CTT\&TCD20180321). G. L. is grateful for Youth Innovation Promotion Association, CAS (2015026).

\section{Notes and references}

1 R. E. Drumright, P. R. Gruber and D. E. Henton, Adv. Mater., 2000, 12, 1841-1846.

2 B. Gupta, N. Revagade and J. Hilborn, Prog. Polym. Sci., 2007, 32, 455-482.

3 R. M. Rasal, A. V. Janorkar and D. E. Hirt, Prog. Polym. Sci., 2010, 35, 338-356. 
4 G. M. Liu, X. Q. Zhang and D. J. Wang, Adv. Mater., 2014, 26, 6905-6911.

5 S. Saeidlou, M. A. Huneault, H. B. Li and C. B. Park, Prog. Polym. Sci., 2012, 37, 1657-1677.

6 L. T. Lim, R. Auras and M. Rubino, Prog. Polym. Sci., 2008, 33, 820-852.

7 T. Gao, Z.-M. Zhang, L. Li, R. Y. Bao, Z. Y. Liu, B. H. Xie, M. B. Yang and W. Yang, ACS Appl. Mater. Interfaces, 2018, 10, 20044-20054.

8 J. Z. Xu, T. Chen, C. L. Yang, Z. M. Li, Y. M. Mao, B. Q. Zeng and B. S. Hsiao, Macromolecules, 2010, 43, 5000-5008.

9 A. M. Pinto, S. Moreira, I. C. Goncalves, F. M. Gama, A. M. Mendes and F. D. Magalhaes, Colloids Surf., B, 2013, 104, 229-238.

10 S. S. Ray and M. Okamoto, Macromol. Rapid Commun., 2003, 24, 815-840.

11 Y. Ikada, K. Jamshidi, H. Tsuji and S. H. Hyon, Macromolecules, 1987, 20, 904-906.

12 H. Tsuji, Macromol. Biosci., 2005, 5, 569-597.

13 K. S. Anderson and M. A. Hillmyer, Polymer, 2006, 47, 20302035.

14 Y. Yin, X. Zhang, Y. Song, S. de Vos, R. Wang, C. A. P. Joziasse, G. Liu and D. Wang, Polymer, 2015, 65, 223-232.

15 H. Tsuji, H. Takai and S. K. Saha, Polymer, 2006, 47, 38263837.

16 T. Wen, Z. J. Xiong, G. M. Liu, X. Q. Zhang, S. de Vos, R. Wang, C. A. P. Joziasse, F. S. Wang and D. J. Wang, Polymer, 2013, 54, 1923-1929.

17 H. Bai, H. Xiu, J. Gao, H. Deng, Q. Zhang, M. Yang and Q. Fu, ACS Appl. Mater. Interfaces, 2012, 4, 897-905.

18 Y. Liu, J. Shao, J. Sun, X. Bian, Z. Chen, G. Li and X. Chen, Mater. Lett., 2015, 155, 94-96.

19 R. Supthanyakul, N. Kaabbuathong and S. Chirachanchai, Polym. Degrad. Stab., 2017, 142, 160-168.
20 R. Y. Wang, S. F. Yang and Y. Zhang, J. Appl. Polym. Sci., 2009, 113, 3630-3637.

21 J. Zhang, S. Wang, D. Zhao, Y. Zhang, W. Pang, B. Zhang and Q. Li, J. Appl. Polym. Sci., 2017, 134, 45194.

22 S. R. Rathi, E. B. Coughlin, S. L. Hsu, C. S. Golub, G. H. Ling and M. J. Tzivanis, Polymer, 2012, 53, 3008-3016.

23 Y. P. Wang, X. Wei, J. Duan, J. H. Yang, N. Zhang, T. Huang and Y. Wang, Chin. J. Polym. Sci., 2017, 35, 386-399.

24 H. Mao, C. Wang, X. Chang, H. Cao, G. Shan, Y. Bao and P. Pan, Mater. Chem. Front., 2018, 2, 313-322.

25 S. Rathi, X. Chen, E. B. Coughlin, S. L. Hsu, C. S. Golub and M. J. Tzivanis, Polymer, 2011, 52, 4184-4188.

26 Y. Liu, J. Shao, J. Sun, X. Bian, L. Feng, S. Xiang, B. Sun, Z. Chen, G. Li and X. Chen, Polym. Degrad. Stab., 2014, 101, 10-17.

27 X. L. Li, R. Wang, C. F. Yang, Z. F. Dong, X. Q. Zhang, D. J. Wang and D. Y. Wang, Acta Polym. Sin., 2018, 5, 598606.

28 Y. Song, D. Wang, N. Jiang and Z. Gan, ACS Sustainable Chem. Eng., 2015, 3, 1492-1500.

29 Z. W. Wilchinsky, J. Appl. Phys., 1960, 31, 1969-1972.

30 G. Liu, Y. Guan, T. Wen, X. Wang, X. Zhang, D. Wang, X. Li, J. Loos, H. Chen, K. Walton and G. Marchand, Polymer, 2011, 52, 5221-5230.

31 J. Zhang, K. Tashiro, H. Tsuji and A. J. Domb, Macromolecules, 2008, 41, 1352-1357.

32 Y. G. Yin, G. M. Liu, Y. Song, X. Q. Zhang, S. de Vos, R. Y. Wang, C. A. P. Joziasse and D. J. Wang, Eur. Polym. J., 2016, 82, 46-56.

33 Z. Kulinski and E. Piorkowska, Polymer, 2005, 46, 1029010300.

34 Z. J. Xiong, G. M. Liu, X. Q. Zhang, T. Wen, S. de Vos, C. Joziasse and D. J. Wang, Polymer, 2013, 54, 964-971. 